\title{
DEVELOPMENT OF A STANDARDIZED FIELDBUS-BASED GREENHOUSE CLIMATE CONTROL
}

\author{
Olga Plaksina, Thomas Rausch \\ Institute of Computer Technology, Vienna University of Technologies \\ Gusshausstrasse 27-29, A-1040 Vienna, Austria \\ \{plaxina,rausch\}@ict.tuwien.ac.at
}

\begin{abstract}
The paper investigates a new application area for standardized control networks which have been primary developed for the use in home and building automation. The work concentrates on the feasibility of building automation technologies for the climate control in growing environments. This includes, but is not limited to, the acquisition and processing of environmental data. The paper analyzes the requirements for greenhouse climate control and compares these demands to those of residential building automation. The authors provide a concept of a KNXbased control system for this application domain and give an outlook on the future phases of the project. Copyright (C) 2005 IFAC
\end{abstract}

Keywords: Agriculture, data handling systems, distributed control, enterprise integration, environment control, fieldbus, knowledge representation.

\section{INTRODUCTION}

Growing crop in greenhouses is an important branch of agriculture and it is a labour intensive and technically challenging business. Optimized control helps to increase production despite saving precious resources. In recent years, growers have invested in a broad range of new technologies, including more efficient growing media, reconstruction of the heating or irrigation equipment itself. In many cases these modifications also involve improvements of associated climate control systems.

The complexity of horticultural production and a growing demand for effective and economic resource management leads to an immediate need for increasing the volume of monitoring and automated control. The number of parameters in greenhouses has been constantly increasing over the last decade (Gieling, 1998). Horticultural structures like greenhouses are very often characterized with significant spreading and decentralization. Therefore the implementation of centralized systems is cumbersome and decreases reliability. A distributed control system exhibits better performance and can be used to improve transparency of the installation and to ease the maintenance. But, in spite of superficial similarities of applications framing climate control in buildings and greenhouses, fieldbus-based building automation/control networks and computerized greenhouse control systems (presented mostly by proprietary solutions) show major differences. That complexity of greenhouse control outperforms regular building automation. Plants grown in covered structures react very sensitive to climatic variances. Therefore the control must be very smooth and constant.

\section{GREENHOUSE CONTROLS vs. BUILDING CONTROLS}

In recent years research on greenhouse climate control has been dealing more with optimization of 
climate models or controlling algorithms (Seginer and McClendon, 1992; Langang, et. al. 2000) rather then with communication techniques. Technical implementations (e.g., Stipanicev and Marasovic, 2003) present applications with newest technology achievements but did not concern on the variety of environmental data and climate models and specific greenhouse requirements. This paper combines both areas, together with integration them into global enterprise information system.

\subsection{A modern greenhouse as a control object.}

A highly dynamic climate is typical for greenhouses (Bailey, 1995). For the comfort in residential buildings, the thermal environment is playing the leading role. An economically and environmentally reasonable system for a modern room climate control concerns a few parameters such as air temperature and velocity, wall and heater surfaces temparature, $\mathrm{CO}_{2}$ concentration, as well as exterior weather conditions (D. Jelondz, 2001). Due to much more intensive response of plants to their environments and the dependance on the outside weather, greenhouse climate conditions are more dynamic comparing to domotics application domain. Moreover, there could be a necessity to change internal climate several times within 24 hours upon diurnal or multi-day schedule depending on the crop and the growing phase (Seginer and McClendon, 1992).

In (Hanan, 1998a) 33 different subset of different factors for greenhouses and plant production can be distinguished. Five of the most important parameters are listed in Table 1.

Table 1 Greenhouse environmental criteria under measurement and subject to control

\begin{tabular}{|c|c|c|}
\hline Main factor & Subsets & Actuators \\
\hline Radiation & $\begin{array}{l}\text { Global radiation } \\
\text { outside, net } \\
\text { radiation, etc. }\end{array}$ & $\begin{array}{l}\text { Shade screens, } \\
\text { supplemental } \\
\text { irradiation }\end{array}$ \\
\hline Temperature & $\begin{array}{l}\text { Outside, inside, } \\
\text { crop and root } \\
\text { zones. Water and } \\
\text { pipe temperature, } \\
\text { etc. }\end{array}$ & $\begin{array}{l}\text { Boilers, } \\
\text { ventilators, } \\
\text { evaporative } \\
\text { pads, thermal } \\
\text { screens, etc. }\end{array}$ \\
\hline Humidity & $\begin{array}{l}\text { Inside and } \\
\text { outside }\end{array}$ & $\begin{array}{l}\text { Misting } \\
\text { systems, } \\
\text { ventilators, } \\
\text { heating } \\
\text { systems }\end{array}$ \\
\hline $\begin{array}{l}\text { Carbon } \\
\text { dioxide }\end{array}$ & $\begin{array}{l}\text { Inside and } \\
\text { outside }\end{array}$ & $\mathrm{CO}_{2}$ injection \\
\hline Wind & Outside, velocity & $\begin{array}{l}\text { Ventilator } \\
\text { systems }\end{array}$ \\
\hline
\end{tabular}

These characteristic values are needed for precise description of interior and exterior climatic conditions of a greenhouse. Building upon these information a control system can influence the internal enviromental conditions. All parameters must be continuously measured and analyzed. Beside the active climate control, the recorded data is of great importance for plant growth related research. Out of this historical information, the grower can apply further improvements to increase the quality and the amount of the crop. This data can be used in the long planning horizon.

Another very important aspect to keep in mind is the tolerance of greenhouse "inhabitants": In residential buildings, temperature fluctuation within some degrees over a particular time interval would not cause serious harm to the tenants. Naturally these fluctuations won't please any inhabitant however if not occurring constantly, these events can be regarded as tolerable inconveniences. For industrial farming failures in the temperature profiles could be vital for the some types of crop and thus lead to serious losses. Therefore even solitary failures in the climatic control must be utterly avoided.

The greenhouse control strategies were developed through years and represent sets of rules defining procedures to bring the interior climatic system to a desired safe state. The operation of the affected equipment is of the major importance since the most climatic parameters rely on the correct functionality of the installed devices. Examples for rules of operation are particular starting sequences for exhaust fans and evaporative pads in order to provide an optimal and efficient cooling process. Proportional, integral and derivative algorithms as well as their combinations are usual for calculating of controlling outputs in greenhouses, though a problem of conflicting requirements and interacting control loops for systems of heating, ventilation, etc. still remains a subject of research (Hanan, 1998). Also physical conditions of operation shall be taken into account to prevent damages of the equipment. In case of snowfall, a shade curtain should be fully open and stay in this position until the snowfall ends; otherwise there is a risk of damage caused by the accumulated snow. Some types of greenhouse-specific equipment (e.g. high-intensity lamps used for supplementary lighting, which are not common for residential buildings) require certain delay after switching off, in order to prohibit rapid reversals.

Similar to buildings, optimization of energy consumption and reduced operation costs are important in a horticultural industry. Additionally, when a greenhouse is operated as business enterprise, the planning horizon usually goes beyond just 24hours continuous operation to solve short-term problems (Hanan, 1998). It spreads over certain longer periods, and provokes development of prospective policies, which could depend on fuel costs, taxes, marketing course, quality of products, etc. In this case, the environmental data and information of current expenditures or energy loads, recorded by the greenhouse control system, could be used for long-term company management, on the one 
hand, and the set-points for the current crop production could be defined by the company's strategy, on the other (e.g. to produce more flowers by exact specific date, and not a week earlier, Fig. 1).

\subsection{Requirements to the system}

Summarizing the features described in the previous sections, it is now possible to formulate the requirements for a KNX-based system for greenhouse climate control:

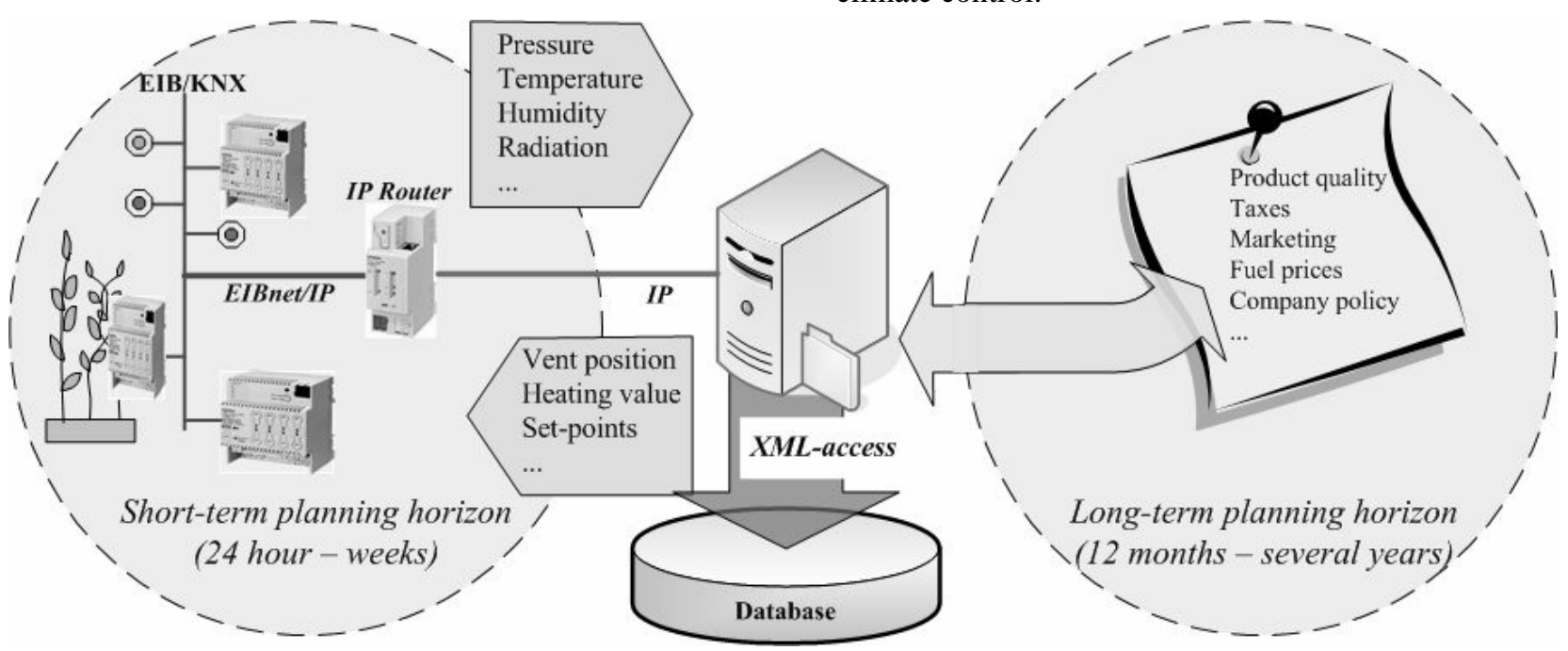

Fig. 1. System architecture from the operational point of view and planning horizons.

\subsection{The importance of standardized control networks.}

KNX is a standardized European technology for control networks. It has evolved mainly from the well-known European Installation Bus (EIB), which is supported by the leading European companies in electrical industry (Dietrich, et al., 2000), but it also bases upon two other field bus technologies: Batibus and the European Home System (EHS).

There are many arguments for using a standardized control network like KNX in comparison to some proprietary technology. Proprietary solutions are not open, in terms of accessible to the public. Only the company or consortium which has developed the particular technology has the legal rights and the technical know-how to use it properly. Standardized network technologies on contrary can be implemented by anyone. As a result, a broad spectrum of different products is available for these technologies (Kastner, 2004). For the customers this also means more safety on their investments. They do not rely on a single company for future extensions, but are able to choose from various vendors. These and other reasons explain why today the majority of projects in building automation are implemented with standardized technologies.

The use of a standardized communication subsystem provides a proven technology which mainly consists of standard components. Due to the complexity of climate control, some special functions will however not be implemented in regular devices found for home and building automation. In this case additional features have to be implemented to fulfil the desired tasks.
- Highly efficient data acquisition and analysis to cope with continuous measurements.

- Accuracy and stability meaning the ability of the system to achieve the desired set-points and control the output with a permissible error.

- Ability to follow the rule sets, which prescribe the sequence of the operation, designed for safe and efficient running of equipment and choosing proper algorithms to avoid energy load peaks.

- Interface for information exchange with enterprise resource planning systems or other company management processes.

These requirements build the basement for the conceptual model of the climatic control system.

\section{CONCEPTUAL MODEL}

This chapter describes a general scheme for the communication between different components of the climate control system. It also illustrates how data is represented in order to achieve the required performance and integrability.

The definition of clean interfaces for each component allows a modular architecture of the system. On the field level (Fig. 2), the KNX bus provides communication between the sensors and the controlling units, which have internal "intelligence". Once the set-points and reaction algorithms are loaded into system components, they do not need a central supervision station and provide with climate maintenance by fulfilling their local tasks. This distributed approach allows more scalability and reliability than traditional centralized systems. 
Though the computing capacity of field controllers is sufficient for local control loops, the system-wide supervision might require complex calculations of new setpoints. These complicated processes run on dedicated servers, which constantly acquire environmental data. The interconnection between the distributed control network and the servers used for additional global control can be established over any internet work.

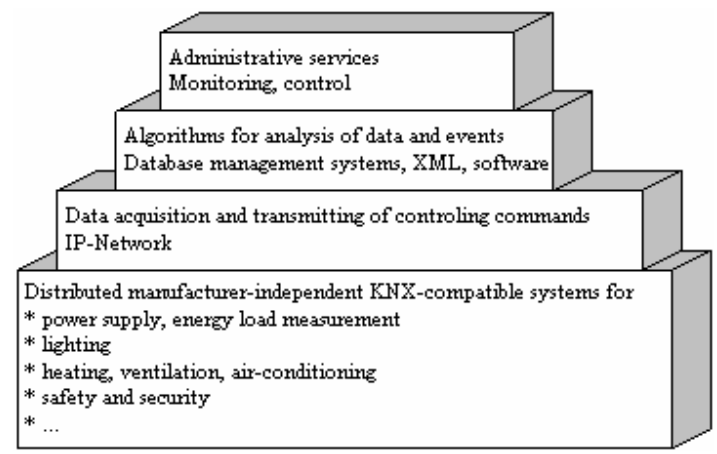

Fig. 2. Modular system architecture.

All data generated in the control network is stored in a database. The server calculates globally optimized controlling commands (e.g. to avoid energy peaks) and set-points (when necessary) and transmits them back to the bus to update the settings of the system components.

The database records should be available for remote data retrieval and greenhouse monitoring, as well as for information exchange with a company management system. The XML technology allows integration of different data sources (Vakali, et. al., 2005) and provides with web-services (e.g. using Internet-resources like weather forecasts).

One of the main advantages of XML data model consists of its ability to work with unstructured data. Structured data is for instance sensory data retrieved from the KNX-telegrams, which can be partition into records with similar fields and therefore stored in a relational database. Unstructured information such as device parameters or greenhouse climate model could have different attributes and needs some other mechanisms to work with. For solving a problem of integration of heterogeneous information sources, a virtual approach based on XML data model seems to be a promising perspective. Data is not physically stored in a centralized unified database but the enduser queries are translated into sub-queries and data is interpreted as if it had unitary logical representation.

\section{CONCLUSION}

The paper comprehends application requirements and conceptual model for a greenhouse control system, which deals with climate control and acquiring of environmental data used for facilitating plant growth activity as well as for horticultural research and greenhouse business management. The model presents a balanced combination of complex distributed control network and information system coverage.

The current work is being focused on investigation and definition of proper knowledge representation formalisms to provide the most efficient processing of the environmental data and development of corresponding XML-enabled data stores. Analysis of control strategies and mechanisms for choosing an optimized one is also a subject of investigation.

\section{REFERENCES}

Bailey, B. J. (1995) Greenhouse Climate Control New Challenges In Greenhouse Environment Control and Automation (Ed. Kano, A.). Acta Hort. Kyoto, Japan.

Cunha, J.B., de Moura Oliveira, J.P. (2003). Optimal management of greenhouse environments In. Proceedings of EFITA 2003 Conference, 5-9 July 2003, pp. 559 - 564. Debrecen, Hungary.

Dietrich, D., Kastner, W., Sauter, T. (2000). Gebäudebussystem, p. 41. Hüthig, Heidelberg.

Gieling, Th. H. (1998) Sensor and Measurement, a Review In II Intrenational Symposium On Sensors in Horticulture (Ed. van Meurs, W. Th. M., Gieling, T. H., Bennedsen, B. S.). Acta Hort. Tune Landboskole, Greve, Denmark.

Hanan, J.J. (1998). Greenhouses: advanced technology for protected horticulture. CRC Press, Boca Raton.

Kastner W. et al. (2004). A Closer Look on Today’s Home and Building Networks In IEEE Africon, 7th Africon Conference in Africa, Technology Innovation, vol. 2 pp. 1239 - 1245.

Jelondz, D., Spasokukotskiy, K., Ruser, H. (2001). Concept and realisation of an EIB based automated room climate control In Proceedings of EIB Conference. Technical University Munich.

Langang, P., Wanliang, W., Qidi, W. (2000). Application of Adaptive Fuzzy Logic System to Model for Greenhouse Climate In 3rd World Congress on Intelligent Control and Automation, pp. 1687 - 1691. Hefei, P.R. China.

Seginer, I., R.W. McClendon (1992). Methods for optimal control of the greenhouse environment In Transactions of the ASAE 35(4)1299-1307.

Stipanicev, D., Marasovic, J. (2003). Networked embedded greenhouse monitoring and control In IEEE Conference on Control Applications, vol. 1, pp. 1350 - 1355.

Vakali, A., Catania, B., Maddalena, A. (2005) XML Data Stores: Emerging Practices In Internet Computing (Ed. Clarke Siobhan), vol. 9, issue 2, pp. 62 - 69. IEEE Computer society. 